Kobry El-Kobbah,

Cairo, Egypt

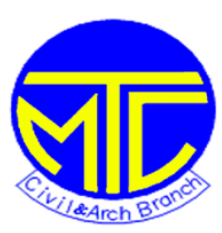
Engineering ICCAE-12-2018

\title{
Blast Hazard Impact on V-Shape Composite Panel Performance
}

\author{
Mostafa Abdel Wahab ${ }^{1}$, Sherif Mazek², Mahmoud Abada ${ }^{3}$, Mohamed Abdel Shafy ${ }^{4}$ \\ ${ }^{(1,2,3)}$ Civil Engineering Department, Military Technical College \\ (4) Tanks Department, Military Technical College, Cairo, Egypt
}

\begin{abstract}
The terrorist attacks have been increased during the last few years. Blast wave propagation is a great engineering challenge to protect structures such as vehicles and buildings. Mitigation systems used to protect the structures remain sophisticated engineering problem.

In this study, the V-shape composite structure is studied as a mitigation system to protect the bottom of vehicles against blast impact. The reviewed field blast test is used from another research conducted by Mazek et al. [1] to verify the proposed numerical model of the V-shape composite structure under the blast effect. The numerical model is proposed by 3-D nonlinear finite element model (FEM). The study presents a comparison between the results obtained by both the field blast test and the FEA to validate the accuracy of the 3-D finite element model.

The effects are expressed in terms of displacement-time history of the V-shape composite structure as the explosive wave propagates. The parametric study is also conducted to study the impact of the V-shape panel inclination on the V-shape composite structure performance under the blast effect. The results obtained by the field blast test have a good agreement with those obtained by the numerical model. The $\mathrm{V}$-shape composite structure improves the armored panel performance under the vehicles based on the impact of detonating different TNT explosive charges.
\end{abstract}




\section{Introduction}

The mitigation system under vehicle body can be used to survive the vehicle from the explosives [2]. The mitigation system performance has a considerable interest for many years [2, 3, and 4]. The Sandwich structures perform better during blast events than metal materials. The sandwich structures offer the additional benefit of a high strength to weight ratio allowing for additional armor to be installed on military vehicles [2, 3, and 4]. Several studies have been discussed sandwich composite structure performance under the impact of blast load [3, 4, 5, and 6].

Xue and Hutchinson [3] discussed the performance of both the sandwich composite structure and the steel plates under the blast effect. The sandwich composite structure performance was higher shock resistance than the steel plate performance at the case of equal mass criteria. Dynamic nonlinear finite element analysis was used to analyze the composite structure and the steel plate. Mori et al. [4] investigated the response of the honeycomb core sandwich structures subjected to blast loading. The sandwich structure was optimized in terms of energy absorption. Vaidya et al. [5] studied the behavior of aluminum foam sandwich plates exposed to blast loading. Mazek and Mostafa [6] used the rigid polyurethane foam (RPF) to strengthen sandwich steel structure under blast load. The field blast test was conducted. They used the finite element analysis (FEA) to model the sandwich steel structure strengthened by the rigid polyurethane foam under shock wave. Abdel Wahab et al. [7] discussed the effect of blast wave on lightweight structures performance experimentally and numerically.

The V-shape structure helps to mitigate the impulse delivered to the vehicle's bottom during a mine blast by deflecting the detonation products away from the body of the vehicle [8]. A flat surface causes a significant pressure concentration beneath the surface [8]. The pressure is trapped between the bottom of the vehicle and the ground. A significant load transfers to the vehicle so the vehicle is thrown upwards into the air. The passengers inside the vehicle could be severe injured and killed by the downwards acceleration of the vehicle. The blast wave propagation is affected by the geometry of the target, as shown in Fig. 1. 

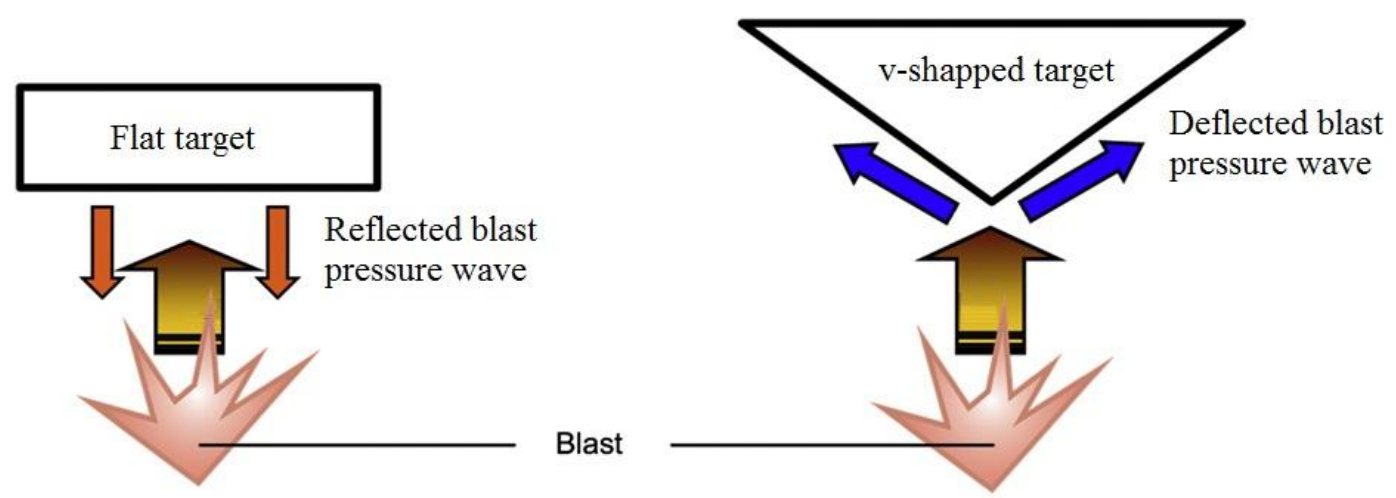

Fig.1: Flow of blast wave hitting flat and V-shape targets

Genson [9] carried out very small scale experiments to investigate mitigation effects of V-shape hulls exposed to buried charges. Ma [10] conducted experimental tests on welded V-shape plates with inclination angles of $90^{\circ}$ and $120^{\circ}$. The V-shape plates were subjected to buried explosives to simulate landmine blast effects. Mazek et al. [1] carried blast field tests for Vshape composite structures to protect vehicles from mining.

This paper aims to study the $\mathrm{V}$-shape composite structure performance so as to protect the bottom of the vehicles from underground explosive. The 3-D numerical model is proposed using finite element analysis (FEA) to study the V-shape composite steel panels to protect the bottom of the vehicles, as shown in Fig. 1. The composite sandwich structure with aluminum foam (ALF) cores strengthened by steel cross ribs is used to study blast mitigation based on constant sheet thicknesses of the ALF. The reviewed field blast test is also used to record maximum displacement at the centre point of the sandwich steel panel. The V-shape composite structure is subjected to a blast wave propagation obtained from detonating of 10-kg TNT explosive charge at a stand-off distance of $1 \mathrm{~m}[1]$. The plastic displacements of the specimen are measured after explosion [1]. The study presents a comparison between the results obtained by both the field blast test and the numerical model to validate the accuracy of the 3-D finite element analysis (FEA). The constitutive model for this analysis contains elasto-plastic materials. An elastoplastic model is employed to represent the performance of the V-shape composite structure and the ALF layer. The proposed model is programmed and linked to an available computer 
program Autodyn3D [13]. The V-shape composite structure model strengthened by the ALF is also implemented in a finite element code Autodyn3D.

The finite element model takes into account the effects of the blast load, the V-shape composite structure, and the ALF. The effects are expressed in terms of the displacement-time history of the V-shape composite structure as the explosive wave propagates. Numerical results obtained by the FEA are compared with the data obtained from the field blast test. Displacement-time history of the V-shape composite structure is presented. Maximum displacements of the V-shape composite structure are recorded and computed by the authors.

The study included a parametric study on the V-shape sandwich structure panels with different inclination angles w.r.t horizontal axis under blast wave propagation. The inclination angles are varied from $0^{\circ}, 12^{\circ}, 16^{\circ}, 20^{\circ}$, up to $22^{\circ}$. The $\mathrm{V}$-shape sandwich structure panels are also subjected to blast wave obtained from detonating of 10-kg and 15-kg TNT explosive charges at a stand-off distance $(\mathrm{R})$ of $1 \mathrm{~m}$. The 3-D FEA is used to understand the effect of inclination angles on the performance of the $\mathrm{V}$-shape sandwich structure. The performance of the $\mathrm{V}$-shape composite structures with different inclination angles is expressed in terms of displacement-time history. The $\mathrm{V}$-shape angles of the composite structure are more efficient parameters to mitigate the blast wave propagation. However, the V-angle of the composite structure is governed by vehicle ground clearance.

\section{Model Validation}

Field blast tests are sometimes impossible to carry out due to safety and environmental constrains [11]. Blast tests conducted in the field face many challenges such as test setup, cost, people injury, environmental risks, and measurements accuracy [11]. The current validation is conducted based on the field blast test carried out by Mazek et al. [1]. This field blast test was conducted using ten-kg TNT explosive located at one-meter away from the top of the V-shape structure. The field blast test was conducted in free air to measure the deformations of the $\mathrm{V}$ shape composite structure [1].

The V-shape panel is a composite sandwich structure filled with ALF cores strengthened by steel cross ribs, as shown in Fig. 2. However, the V-shape structure was used as a mitigation system 
to protect the bottom of vehicle from blast impact. The test specimen consists of two face-sheets are made of normal mild steel with inclination angles $\left(22^{\circ}\right.$ and $\left.16^{\circ}\right)$, as shown in Fig. 2.

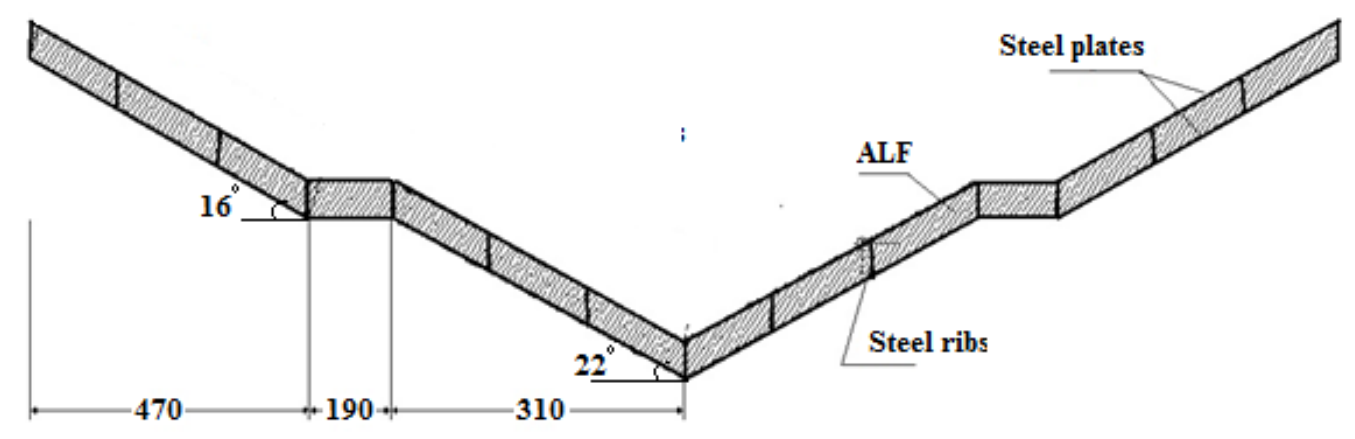

Fig. 2: The geometry of the V-shape composite structure (after Mazek et al. [1])

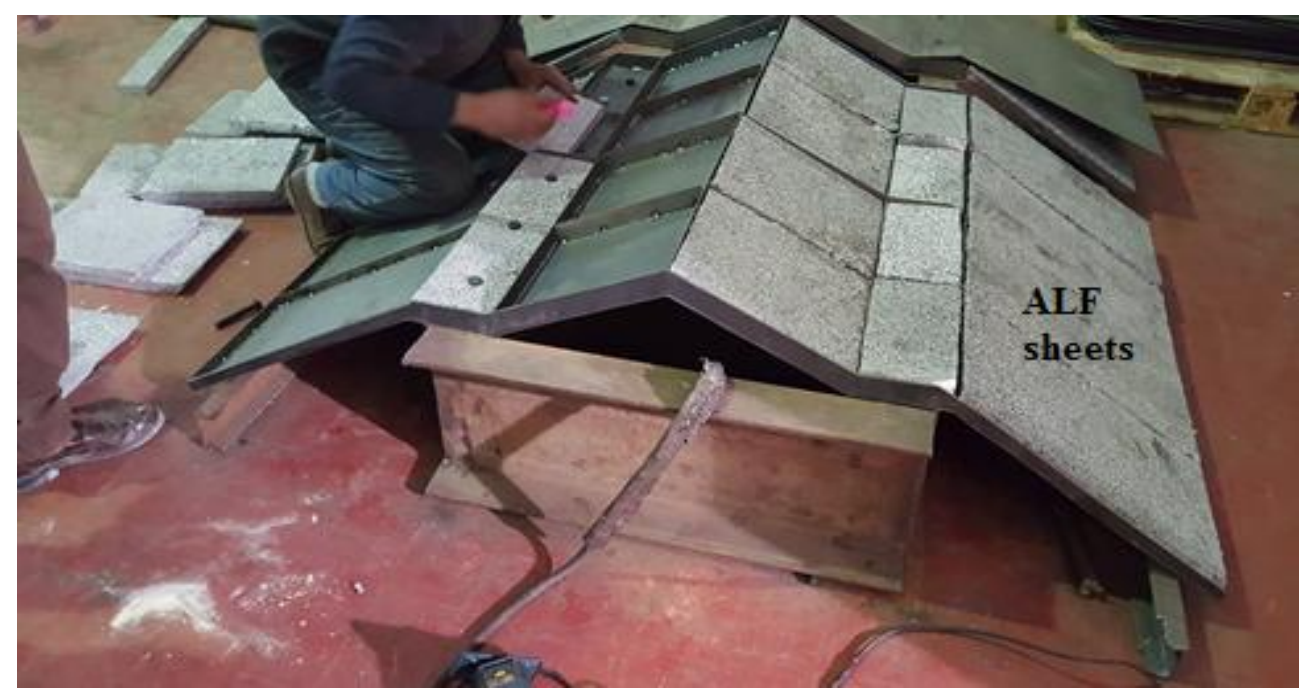

Fig. 3: The use of ALF as a filling material for the V-shape composite structure (after Mazek et al. [1])

The V-shape composite structure was strengthened by steel cross ribs between the outer steel plates, as shown in Fig. 2. The thicknesses of the outer steel plates are $5 \mathrm{~mm}$. The V-shape 
composite structure was also filled with the ALF, as shown in Fig. 3. The thickness of the steel cross ribs is $4 \mathrm{~mm}$ and the height of the steel cross ribs is $34 \mathrm{~mm}$. Steel ribs were welded on the lower steel sheet with $300 \mathrm{~mm}$ internal spaces, as shown in Fig. 3. These internal spaces were filled with ALF sheets, as shown in Fig. 3. The specimen was welded onto test rig (vehicle's chassis), as shown in Fig. 3. The previous specimen was prepared and assembled with special requirements to be tested against TNT explosive [1].

Ten-kg TNT explosive charge was installed at the middle of the test rig frame. The explosive charge was hanged with wire rounded on steel pipe of the charge holder frame, as shown in Fig. 4. The vertical distance between the TNT charge and the crown of the specimen was one meter, as shown in Fig. 4.

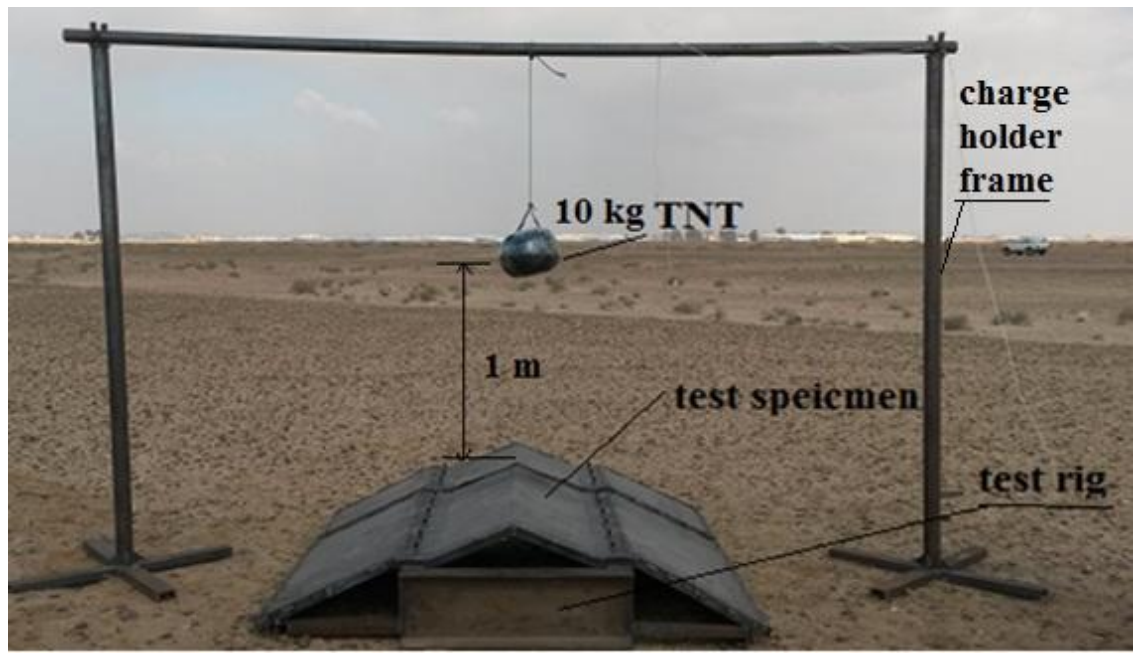

Fig. 4: 10-kg TNT explosive charge was hanged on charge holder (after Mazek et al. [1])

The test specimen was placed in the setup frame configuration and the TNT explosive was also set, as shown in Fig. 4. High speed camera was used to capture the blast wave propagation, as 
shown in Fig. 5. The fireball and blast wave generated in free air are shown in Fig. 6. The Vshape structure strengthened by both the steel cross ribs and ALF was deformed, as shown in Fig. 7.

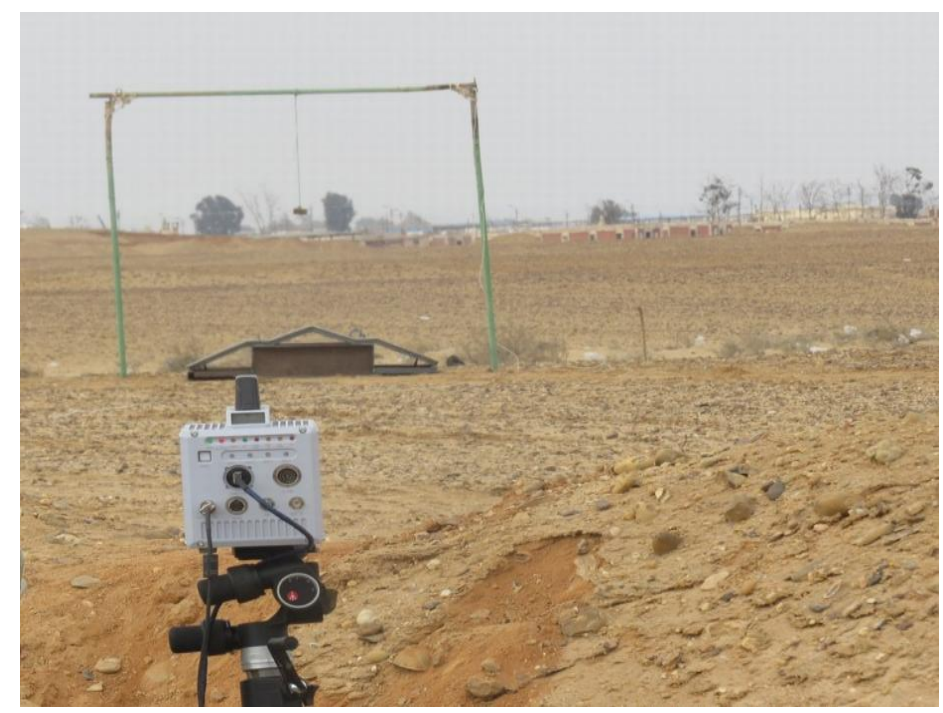

Fig. 5: High speed camera used in the field blast test (after Mazek et al. [1])

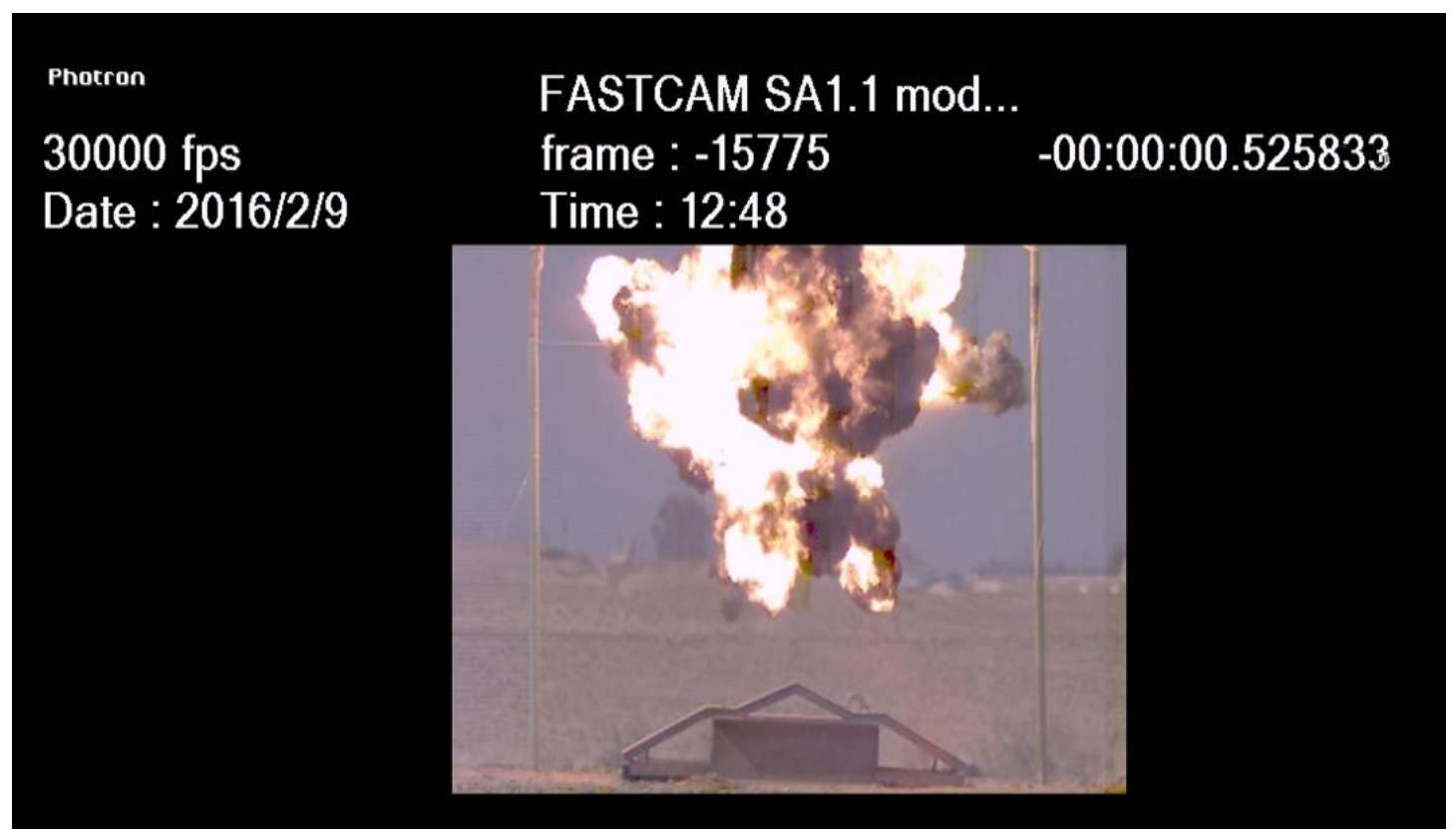

Fig. 6: Explosive scene by 10-kg TNT explosive (after Mazek et al. [1]). 


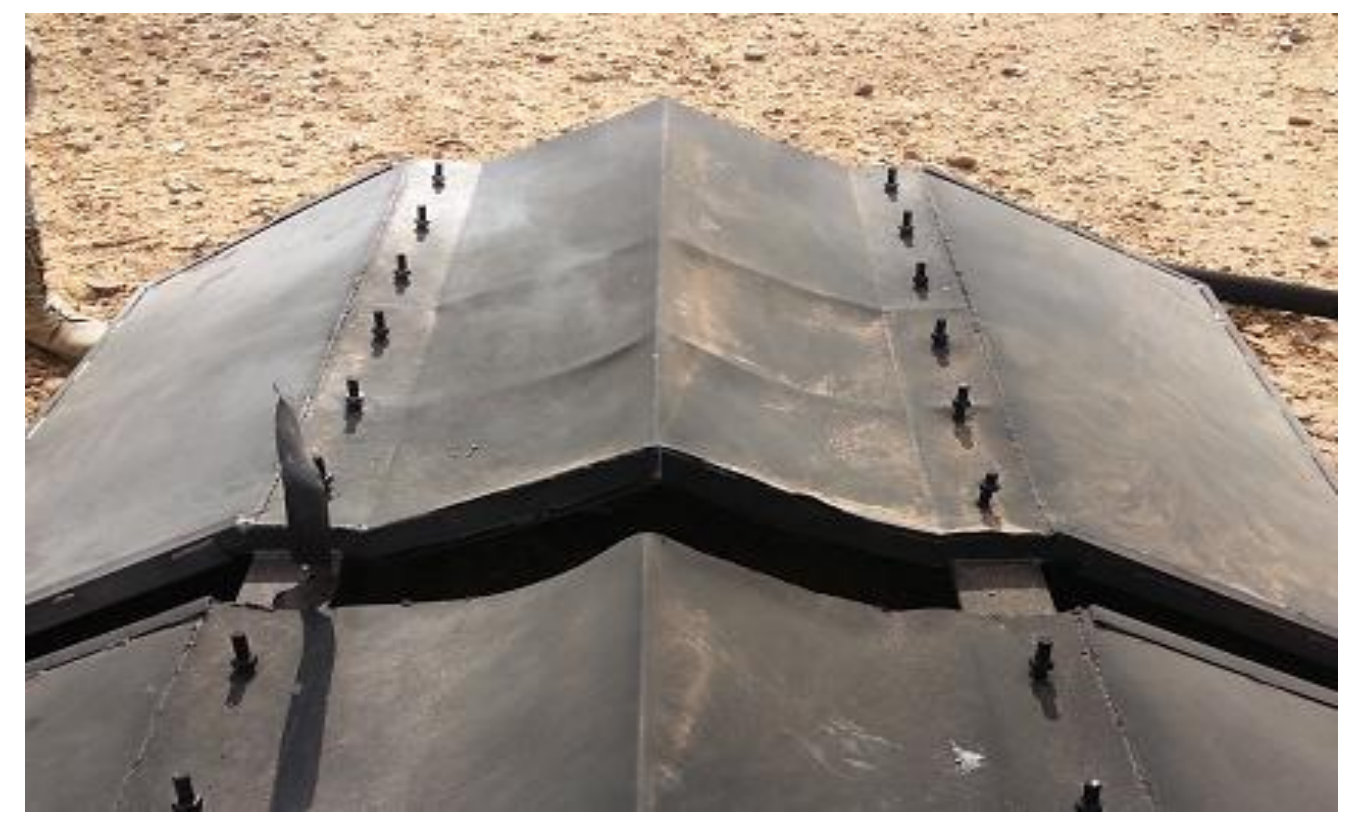

Fig. 7: Test specimen strengthened by the steel cross ribs and ALF after explosion (after Mazek et al. [1]).

The plastic deformations of the specimen were measured after the impact of the explosion, as tabulated in Table. 1. The behavior of the $\mathrm{V}$-shape composite structure was investigated under blast wave obtained from 10-kg TNT explosive charge at a stand-off distance of $1 \mathrm{~m}$.

The three-dimensional finite element model is used to simulate the dynamic response of the Vshape composite structure under the impact of blast load. The numerical analysis is carried out using ANSYS/AUTODYN which is specifically designed for non-linear dynamic analysis and widely used to simulate blast loading [12]. In numerical modeling, air and equivalent TNT explosive are simulated by Euler processor. The air and the equivalent TNT explosive are assumed to satisfy the equation of state (EOS) of ideal gas [12]. The standard constants of air and TNT are obtained from the AUTODYN -3D material library. These include air initial internal energy $E_{n}=2.068 \times 10^{5} \mathrm{~kJ} / \mathrm{kg}$; air mass density $\rho=1.225 \mathrm{~kg} / \mathrm{m}^{3}$; and ideal air constant $\gamma=1.4$. The data that defines the steel plates (Steel 1006) material are chosen from the library and modified. The linear equation of state and strength model is applied. The yield stress of steel is assumed $3.5 \times 10^{5} \mathrm{kPa}$ and its shear modulus was $8.18 \times 10^{7} \mathrm{kPa}$. Ribs and face sheets are simulated by shell elements, and ALF is simulated by solid elements, as shown in Fig. 8. The V-shape structure was 
welded onto the chassis, as shown in Fig. 4. The V-shape structure was fixed at welding places as shown in Fig. 9. The model is conducted in AUTODYN. The blast wave from detonation of $10 \mathrm{~kg}$ TNT is striking the V-shape structure. The displacement-time history is obtained and shown in Fig. 10. The maximum displacement is $50 \mathrm{~mm}$. The numerical model can well predict the blasting-induced pressure on steel structures, as shown in Fig. 11.

Table. 1: Plastic deformations as computed by the numerical analysis compared against field blast test results.

\begin{tabular}{|l|c|c|c|}
\hline \multicolumn{1}{|c|}{ location } & $\begin{array}{c}\text { Plastic deformations } \\
\text { computed by the 3-D } \\
\text { FEM } \\
(\mathrm{mm})\end{array}$ & $\begin{array}{c}\text { Plastic deformations } \\
\text { measured by the field test } \\
(\mathrm{mm})\end{array}$ & $\begin{array}{c}\text { Discrepancy } \\
(\%)\end{array}$ \\
\hline Gauge 2 & 44.54 & 50 & $10.9 \%$ \\
\hline Gauge 4 & 28.62 & 30 & $4.6 \%$ \\
\hline Gauge 8 & 10.01 & 10 & $0.1 \%$ \\
\hline Gauge 9 & 3 & 0 & - \\
\hline
\end{tabular}

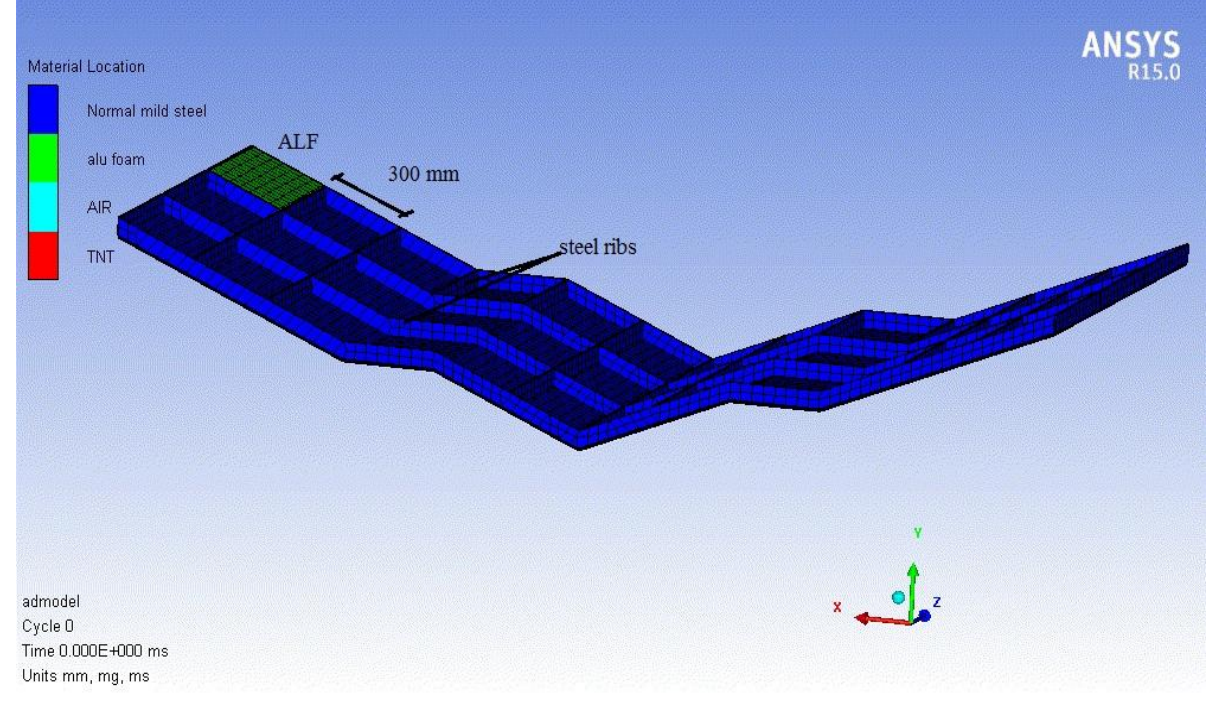

Fig. 8: 3-D finite element model of V-shape composite structure. 


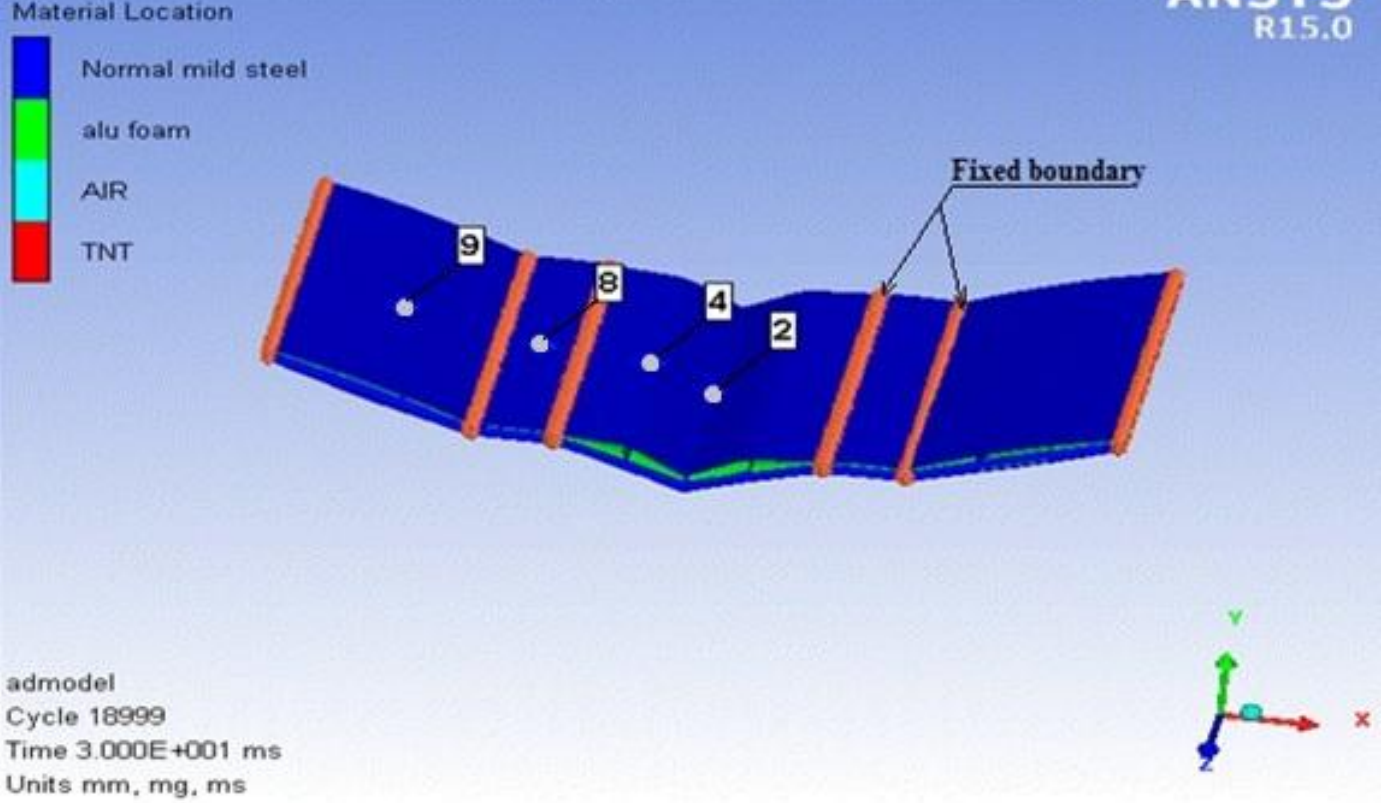

Fig. 9: Gauge locations and boundary conditions.

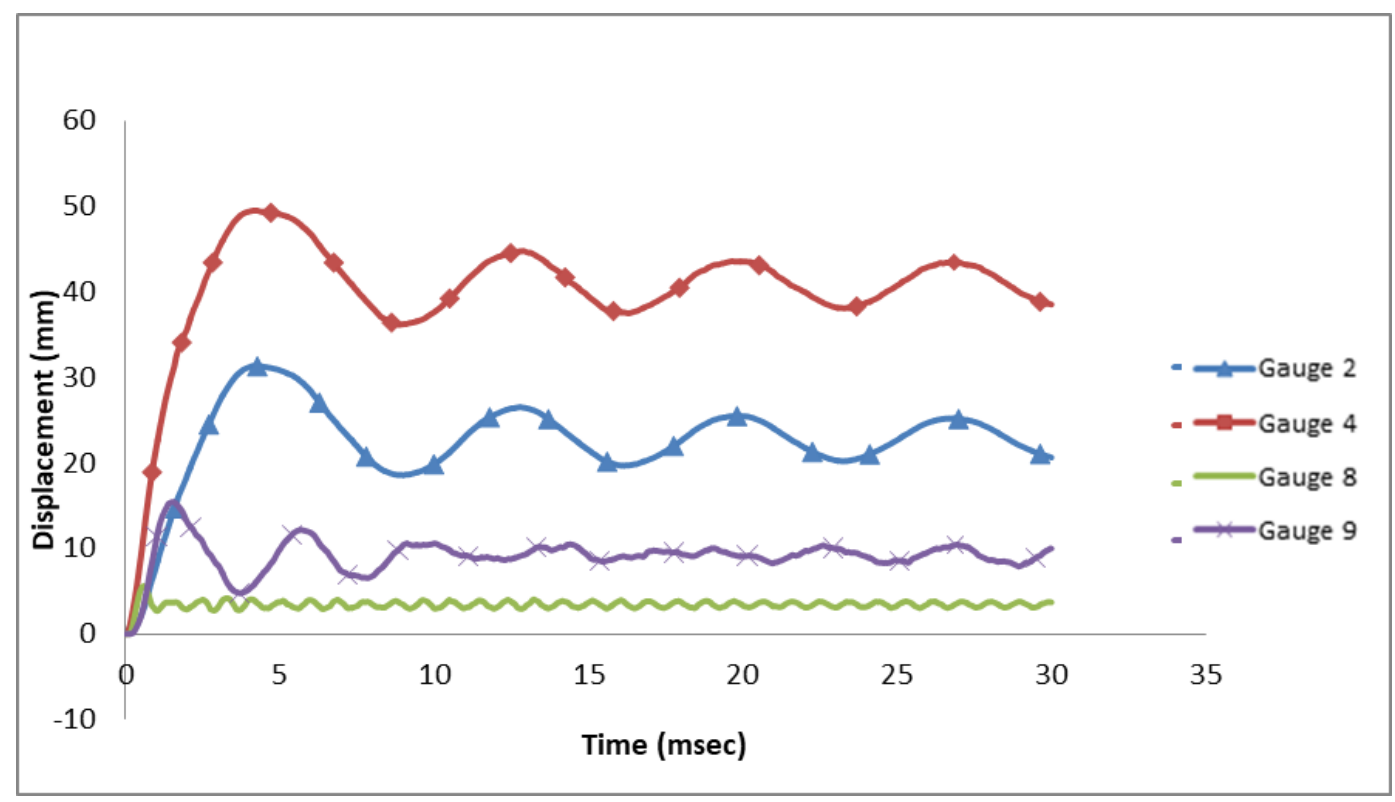


Fig. 10: Displacement-time history profiles at different gauges of the V-shape structure subjected to detonation of $10-\mathrm{kg}$ TNT.

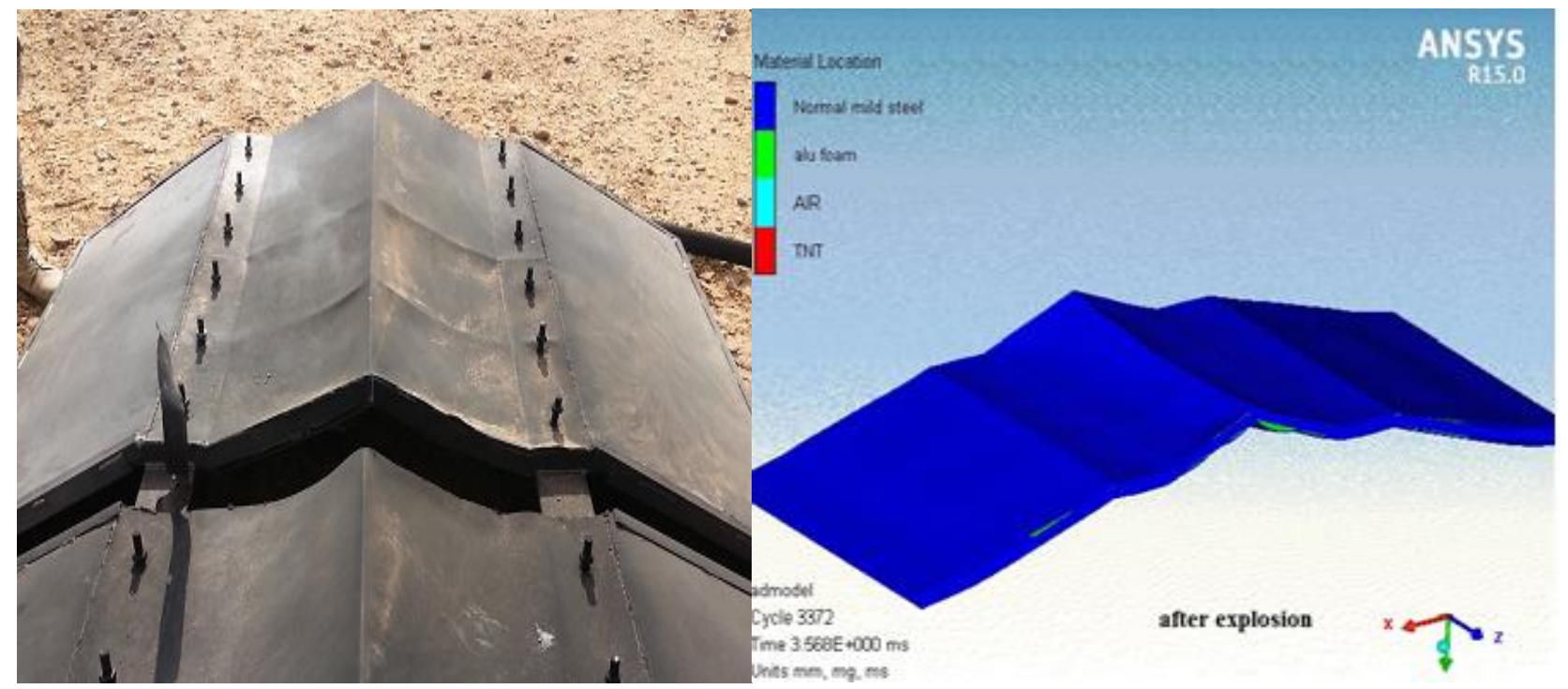

Fig. 11: Field blast test specimen and the 3-D FEM after the detonation of $10 \mathrm{~kg}$ TNT.

\section{Performance of $\mathrm{V}$-shape structure under blast effect}

This study discusses the effect of inclination angle on the performance of the $\mathrm{V}$-shape structure. The performance of the V-shape structures with different inclination angles is investigated using the 3-D FEA. The inclination angle $(\phi)$ of the $\mathrm{V}$-shape composite structures is varied from $0^{\circ}$, $12^{\circ}, 16^{\circ}, 20^{\circ}$, up to $22^{\circ}$, as shown in Fig. 12. The $\phi$ angle is varied to discuss the effect of blast wave propagation on the flat and $\mathrm{V}$-shape composite structure. The $\mathrm{V}$-shape structures are subjected to blast wave obtained from detonating of 10-kg and 15-kg TNT explosive charges at a stand-off distance of $1 \mathrm{~m}$.

The V-shape sandwich structure is composed of ALF as core material and outer mild steel plates strengthen by the inner steel cross ribs. The interior space between the cross ribs in two directions is $30 \mathrm{~cm}$, as shown in Fig. 13. The steel of the outer plates and the cross ribs is normal mild steel. The thickness of the steel plate facing the TNT charge is $3 \mathrm{~mm}$. The thickness of the 
back steel plate is $4 \mathrm{~mm}$. the interior space between face steel plate and the back steel plate is 34 $\mathrm{mm}$, as shown in Fig. 14.

The dimensions of the V-shape sandwich structures are $900 \mathrm{~mm}$ length and $600 \mathrm{~mm}$ width, as shown in Fig. 14. The inclination angle $(\phi)$ of the V-shape structures is varied from $0^{\circ}, 12^{\circ}, 16^{\circ}$, $20^{\circ}$, upto $22^{\circ}$ as shown in Fig. 15. The V-shape structures were fixed from four edges and subjected to a surface detonation of $10-\mathrm{kg}$ and $15-\mathrm{kg}$ TNT explosive charges at a stand-off distance of $1 \mathrm{~m}$ from the front face-sheet along the centerline of the panel as shown in Fig. 15.

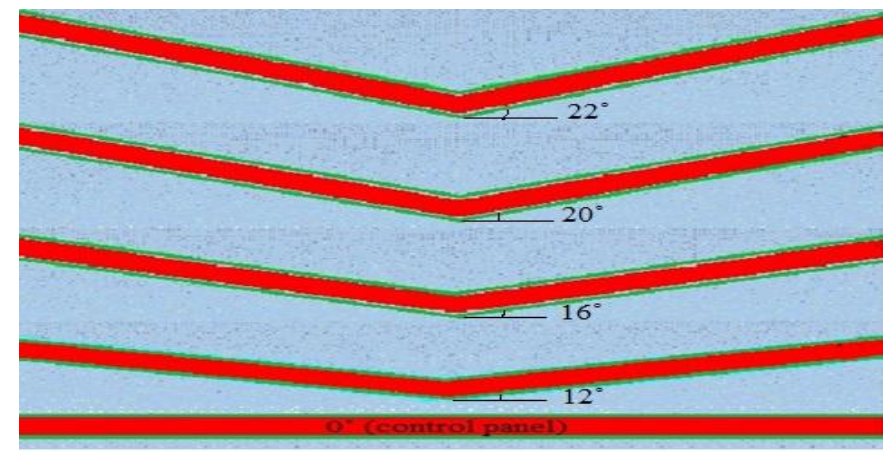

Fig. 12: Variation of inclination angle $(\phi)$ of the V-shape composite structures.

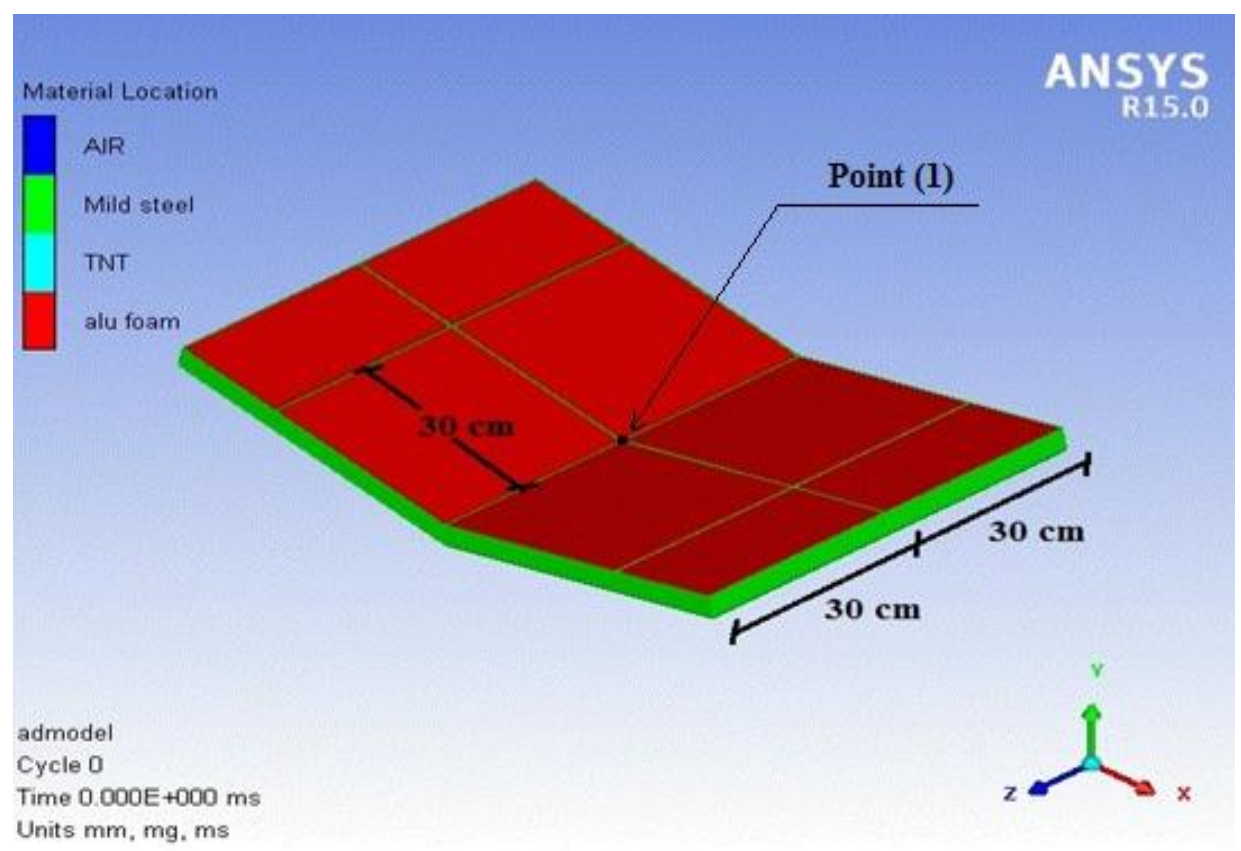


Fig. 13: V-shape composite structure strengthened by steel ribs with interior distance of $30 \mathrm{~cm}$ filled with ALF as a core material.

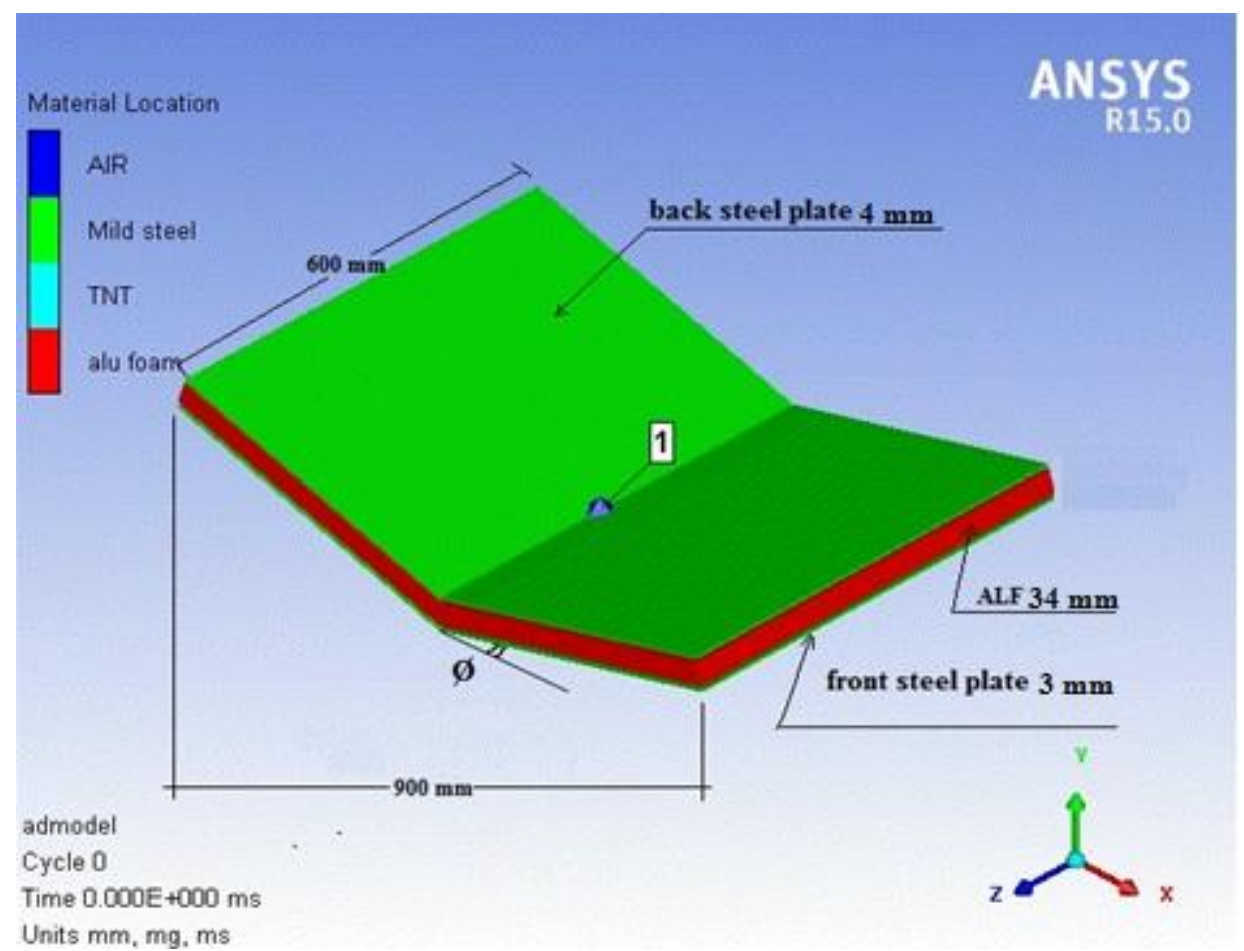

Fig. 14: The V-Shape Sandwich Structure.

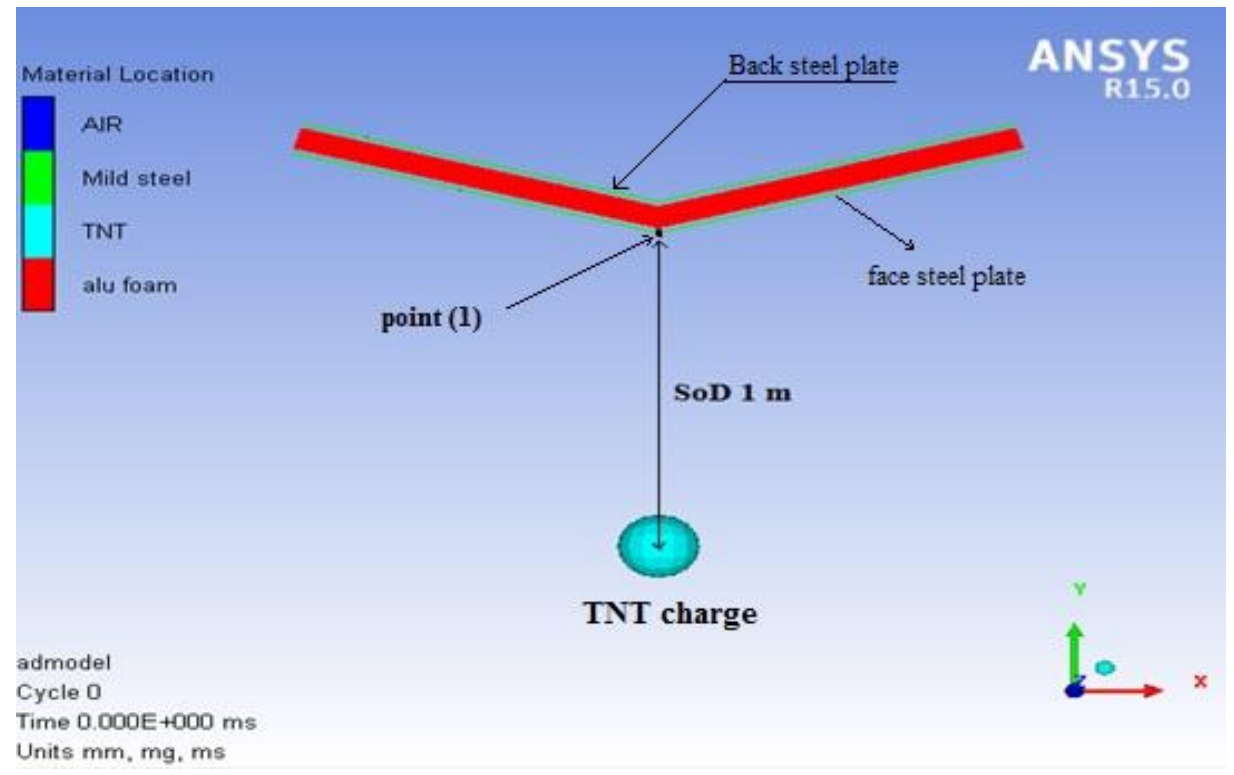


Fig. 15: Loading condition of V-shape composite structures.

\section{Modelling of V-shape Composite Structures}

In numerical modeling, air and equivalent TNT explosive are simulated by Euler processor. The air and the equivalent TNT explosive are assumed to satisfy the equation of state (EOS) of ideal gas [57]. Shell element is used to simulate the behavior of the steel plates and steel ribs. Solid element is used to simulate the behavior of ALF sheets. Flow-out boundary is used to reduce reflection of stress wave from the numerical boundaries. The standard constants of air and TNT explosive are obtained from the AUTODYN-3D material library. This library includes air initial internal energy $E_{n}=2.068 \times 10^{5} \mathrm{~kJ} / \mathrm{kg}$; air mass density $\rho=1.225 \mathrm{~kg} / \mathrm{m} 3$; and ideal air constant $\gamma$ $=1.4$. The boundary condition applied to the structure is fixed from all edges.

A 4-node rectangular shell element is used to model the steel plates, and the steel ribs. Shell element consists of 4-node rectangular shape each node having 6 degrees of freedom (three translations and three rotations). The shell element allows both the membrane (in-plane) and the bending (out-of-plane).

A solid element is also used to model the ALF core material. The solid element is chosen since it possesses in-plane and out-of-plane stiffness. The solid element allows for both in-plane and outof-plane loads. The solid element is cubic in shape and has 8 nodes each node having 3 degrees of freedom (three translations). 


\section{Impact of Inclination Angle on the Performance of V-shape Structures}

The performance of V-shape composite structures is discussed based on different inclination angles. The displacement-time history of V-shape composite structures due to blast load is calculated using the proposed 3-D FEM.

Ten-kg TNT explosive is used to discuss the performance of the V-shape structures with different inclination angles under impact of blast load. The TNT explosive charge is located at stand-off distance of one meter from the center of the crown of the structure, at point (1). Figures 16 show the displacement-time history results for each case.

Fifteen-kg TNT explosive is used to discuss the performance of the V-shape composite sandwich structures with different inclination angles under impact of blast load. The TNT explosive charge is located at stand-off distance of one meter from the center of the crown of the structure, at point (1). The displacement-time history profiles at the center of the crown of the panels are calculated for each case, as shown in Fig. 17. The plastic deflections at point (1) due to the blast impact are tabulated in Table 2.

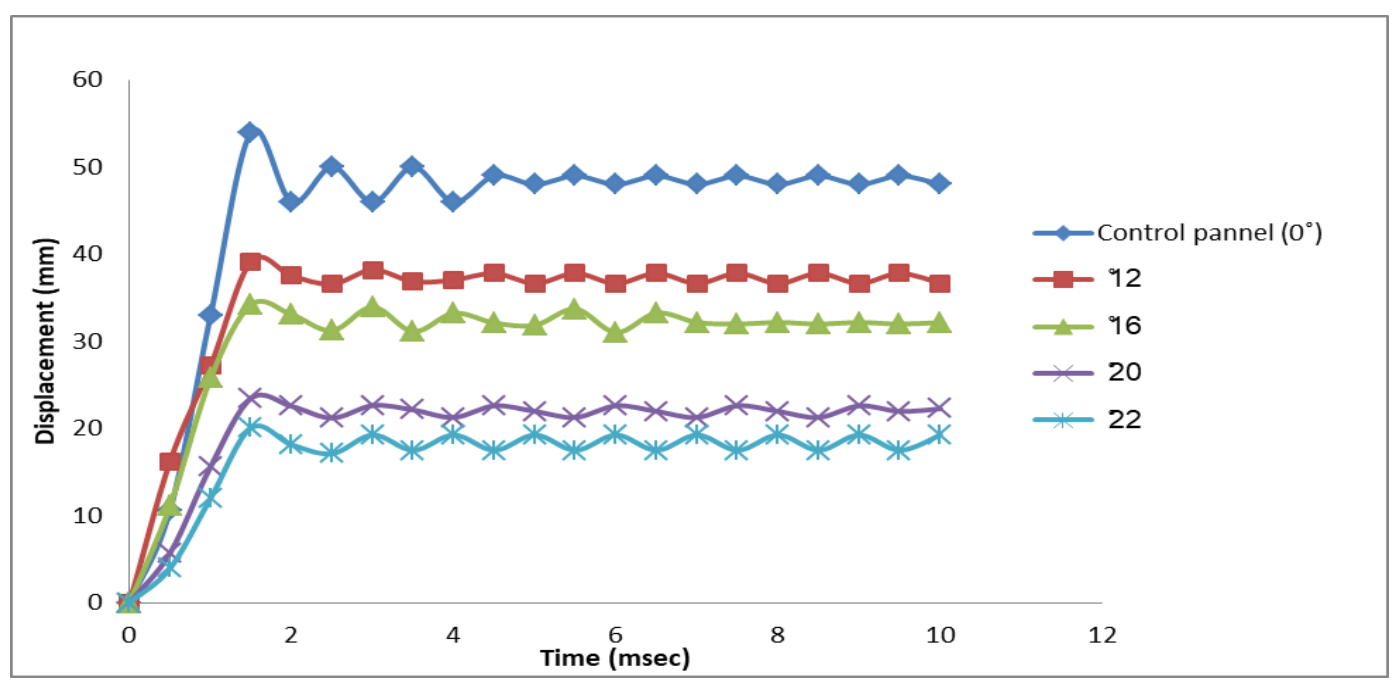

Fig. 16: Displacement-time history of V-shape composite structures with different inclination angles subjected to detonation of 10-kg TNT. 


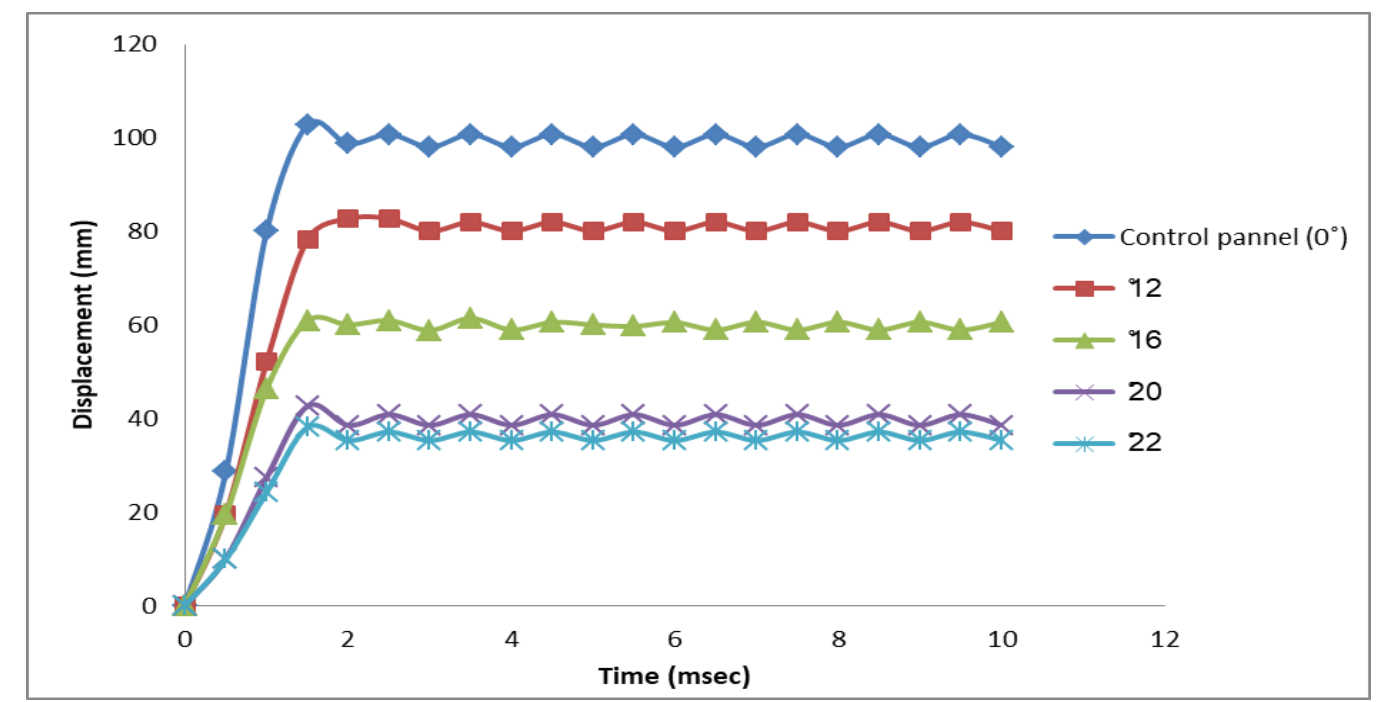

Fig. 17: Displacement-time history of V-shape composite structures with different inclination angles subjected to detonation of $15-\mathrm{kg}$ TNT.

Table. 2: Plastic deformations at point (1) due to the impact of blast load for panels with included angles

\begin{tabular}{|c|c|c|c|c|c|c|}
\hline $\begin{array}{l}\text { Core of } \\
\text { composite } \\
\text { structure }\end{array}$ & $\begin{array}{c}\text { Inclination angle } \\
\phi(\text { degree })\end{array}$ & $\begin{array}{c}\text { Charge } \\
\text { Weight } \\
\text { (kg) }\end{array}$ & $\begin{array}{l}\text { SoD } \\
(\mathrm{m})\end{array}$ & $\begin{array}{c}\text { Pressure } \\
\text { (bar) }\end{array}$ & $\begin{array}{c}\text { Plastic } \\
\text { deformation } \\
(\mathrm{mm})\end{array}$ & $\begin{array}{c}\text { Discrepancy } \\
(\%)\end{array}$ \\
\hline \multirow{5}{*}{$\begin{array}{c}\text { ALF+ ribs } \\
30\end{array}$} & $0^{\circ}$ (control panel) & \multirow{5}{*}{10} & \multirow{5}{*}{1} & \multirow{5}{*}{44.5} & 49.72 & - \\
\hline & $12^{\circ}$ & & & & 38.4 & $22 \%$ \\
\hline & $16^{\circ}$ & & & & 33.22 & $33 \%$ \\
\hline & $20^{\circ}$ & & & & 23.13 & $50 \%$ \\
\hline & $22^{\circ}$ & & & & 19.6 & $60 \%$ \\
\hline \multirow{5}{*}{$\begin{array}{c}\text { ALF+ ribs } \\
30\end{array}$} & $0^{\circ}$ (control panel) & \multirow{5}{*}{15} & \multirow{5}{*}{1} & \multirow{5}{*}{57.9} & 100.05 & - \\
\hline & $12^{\circ}$ & & & & 80.3 & $20 \%$ \\
\hline & $16^{\circ}$ & & & & 60.9 & $40 \%$ \\
\hline & $20^{\circ}$ & & & & 40.3 & $60 \%$ \\
\hline & $22^{\circ}$ & & & & 37.7 & $62 \%$ \\
\hline
\end{tabular}


Results show that the bigger inclination angle $(\phi)$ the better blast mitigation. However, the Vshape structure for a vehicle's bottom would ideally be limited inclined angle to save a suitable clearance between the bottom and ground surface.

\section{Conclusions}

- A 3-D nonlinear finite element analysis has been used to study the effect of inclination angle on the performance of the $\mathrm{V}$-shape composite structure.

- The FEA is used to predict the response of V-shape composite structures with different inclination angles due to the detonation of $10-\mathrm{kg}$ and $15-\mathrm{kg}$ TNT explosive charges placed at $1 \mathrm{~m}$ SoD from the center of the panel.

- The responses of the $\mathrm{V}$-shape composite structure with inclination angle $12^{\circ}$ are reduced by up to $15 \%$ with respect to those of flat composite structures.

- The responses of the $\mathrm{V}$-shape composite structure with inclination angle $16^{\circ}$ are reduced by up to $25 \%$ with respect to those of flat composite structures.

- The responses of the $\mathrm{V}$-shape composite structure with inclination angle $20^{\circ}$ are reduced by up to $40 \%$ with respect to those of flat composite structures.

- The responses of the $\mathrm{V}$-shape composite structure with inclination angle $22^{\circ}$ are reduced by up to $50 \%$ with respect to those of flat composite structure.

- The results indicate that the response of the V-shape structure decreases with increase the inclined angle $(\phi)$. So, the V-shape protective shield is superior to a flat- protective shield in resisting loads transfer from an explosive blast.

- The V-shape composite structure is used as a protective layer to protect the bottom of a vehicle from blast load.

- The reviewed field blast test is used to study the performance of the V-shape composite structure. The 3-D finite element model is used to simulate the field blast test and to predict the performance of the composite structure.

- Extensive parametric study is conducted to adopt the $\mathrm{V}$-shape composite structure to protect bottom of the armored vehicles under blast load. 


\section{References}

[1] S. A. Mazek and his clleagues. Design and manufacture of protective systems for armored veichles against blast wave impact: Technical report, Egyption Army. Cairo. Egypt, 2016.

[2] Condon, J.A., Gniazdowski, N., and Gregory, F.H. The Design, Testing, and Analysis of a Proposed Composite Hull Technology Mine-BlastResistant Vehicle Floor Panel. ARL-TR-796, 1995.

[3] Z. Xue and J. W. Hutchinson. Preliminary assessment of sandwich plates subject to blast loads. International Journal of Mechanical Sciences, vol. 45, pp. 687-705, 2003.

[4] L. Mori, et al. Deformation and fracture modes of sandwich structures subjected to underwater impulsive loads. Journal of mechanics of materials and structures, vol. 2, pp. 1981-2006, 2007.

[5] R. Sriram and U. K. Vaidya. Blast impact on aluminum foam composite sandwich panels. Proceedings of the 8th International LS-DYNA Users Conference. 2004.

[6] S. A. Mazek and A. A. Mostafa. Impact of a shock wave on a structure strengthened by rigid polyurethane foam. Structural Engineering and Mechanics, vol. 48, pp. 569-585, 2013.

[7] Mostafa M. Abdel Wahab, S. A. Mazek, Mahmoud. M. Abada and a. M. H. A. Shafy. Effect of blast wave on lightweight structure performance. Journal of Engineering Science and Military Technologies, vol. 1, 2017.

[8] S. C. K. Yuen, G. S. Langdon, G. N. Nurick, E. G. Pickering, and V. H. Balden. Response of Vshape plates to localised blast load: Experiments and numerical simulation. International journal of impact engineering, vol. 46, pp. 97-109, 2012.

[9] K. W. Genson. Vehicle haping for mine blast damage reduction. 2006.

[10] G. Ma. Modeling of wave propagation induced by underground explosion. Computers and Geotechnics. vol. 22, pp. 283-303, 1998.

[11] V. Balden and G. Nurick. Numerical simulation of the post-failure motion of steel plates subjected to blast loading. International journal of impact engineering, vol. 32, pp. 14-34, 2005.

[12] H. Hao. Numerical simulation of underground explosions. Fragblast, vol. 2, pp. 383-395, 1998.

[13] AUTODYN, “Theory Manuals”, Version 6.1, Century Dynamics Inc., Sam Ramon, USA, 2005. 